\title{
Assessing Longitudinal Arterial Performance and Traffic Signal \\ Retiming Outcomes
}
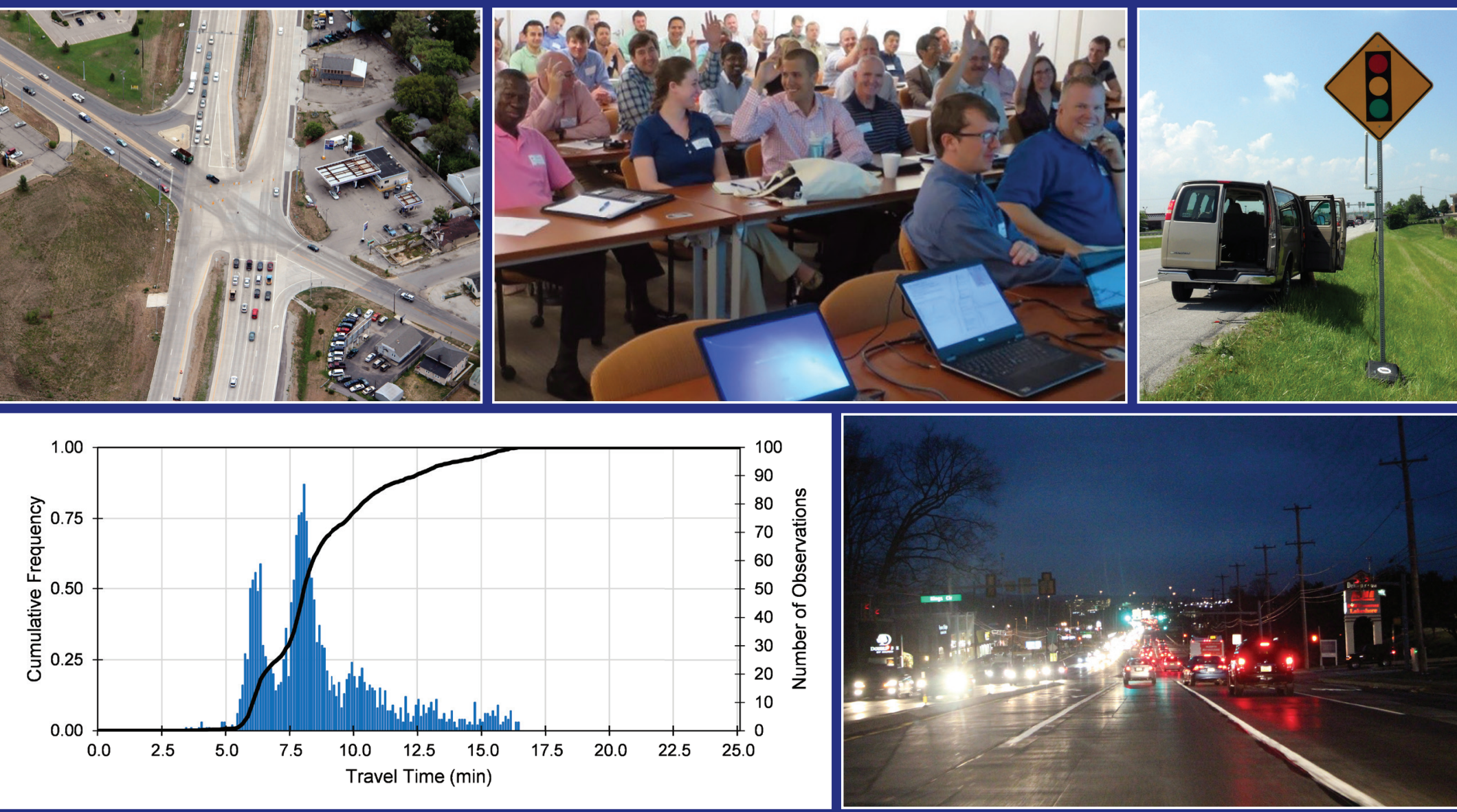

Steven M. Lavrenz, Christopher M. Day, W. Benjamin Smith, James R. Sturdevant, Darcy M. Bullock 


\title{
Assessing Longitudinal Arterial Performance and Traffic Signal Retiming Outcomes
}

\author{
Steven M. Lavrenz \\ Purdue University \\ Christopher M. Day \\ Purdue University \\ W. Benjamin Smith \\ Indiana Department of Transportation \\ James R. Sturdevant \\ Indiana Department of Transportation \\ Darcy M. Bullock \\ Purdue University
}
SBIR Phase 3 Joint Transportation Research Project
Traffax, Inc.
Purdue University

September 4, 2015

\begin{tabular}{|l|l|}
\hline Deliverable Reference: & D1.8a Case Study \#1 \\
\hline Project Name: & $\begin{array}{l}\text { Sensor Fusion and MOE Development for Off-Line } \\
\text { Traffic Analysis of Real Time Data }\end{array}$ \\
\hline Contractor: & Traffax, Inc. \\
\hline Contract Number: & DTFH61-14-C-00035 \\
\hline Contract Term Start & $9 / 4 / 2014$ \\
\hline Contract Term End & $9 / 4 / 2017$ \\
\hline Key Personnel & Stan Young, Darcy Bullock, Dennis So Ting Fong \\
\hline
\end{tabular}




\section{Recommended Citation}

Lavrenz, S. M., C. M. Day, W. B. Smith, J. R. Sturdevant, and D. M. Bullock. Assessing Longitudinal Arterial Performance and Traffic Signal Retiming Outcomes. Purdue University, West Lafayette, Indiana, 2017. https://doi.org/10.5703/1288284316563

\section{Acknowledgments}

This work was supported by Traffax/USDOT SBIR DTFH6114C00035. The contents of this paper reflect the views of the authors, who are responsible for the facts and the accuracy of the data presented herein, and do not necessarily reflect the official views or policies of the sponsoring organizations. These contents do not constitute a standard, specification, or regulation. 


\section{Abstract}

Agencies often find it difficult to justify investments in active traffic management. Historically, it has been a challenge to obtain data that would help make the case for those investments. While new data sources have emerged recently, there remains very little documentation of the potential long term benefits from signal retiming using associated performance measures. This study presents a use case for an active traffic management strategy on a signalized corridor over a 5-year period, during which traffic volumes increased by approximately 36\%, and offset optimization was performed every 2-3 years. Despite the considerable volume growth, arrivals on green were increased by more than $41 \%$, and the percentage of vehicles arriving on green increased by $10 \%$, a gain of 6 percentage points. Furthermore, drivers experienced an average of $5 \%$ reduction in travel time and travel time reliability costs after each optimization. This resulted in a total user benefit over the 5-year period of approximately \$3.6 million. Agencies can utilize these strategies to quantitatively assess how traffic performance and signal timing degrade over time, in a manner similar to physical infrastructure assets. The results highlight the benefits and associated business case of adopting a long-term active traffic management strategy, based on datadriven performance monitoring and decision making. 


\section{Introduction}

Every year, agencies spend approximately $\$ 1$ billion on traffic signal-related maintenance and upgrades. Approximately half of this goes to maintenance and repair of physical infrastructure, while only $20 \%$ is dedicated to retiming and optimization of progression (1). Many agencies are reluctant to dedicate a larger percentage of their budgets for routine retiming, due in part to considerable uncertainty about how traffic signal timing "ages" in response to changing volumes and travel patterns. As a result, agencies often retime corridors on fixed schedules or according to "rule-of-thumb" estimates, rather than considering data-driven performance measures (2).

Historically, studies examining longer-term microscopic trends in traffic performance have approached the topic from an external perspective, without active intervention on the system(s) in question. For instance, Day et al. compiled a statewide, multi-year ranking of signalized corridors using measures of travel time and travel time reliability (3). The extent to which specific timing plan modifications impacted these travel times was not extensively considered. Numerous other research programs have been established for the purpose of passively monitoring corridor travel time and travel time reliability (4, 5, 6). For those studies which do consider active signal timing intervention over a number of years, the primary focus has been on fully automated solutions, such as adaptive traffic control. For example, Stevanovic et al. conducted a 10-year evaluation of the SCATS system in Utah, using microsimulation, and found that data-driven timing strategies offered substantially improved performance to static timing plans (7).

One notable study which previously estimated large-scale, long-term performance measures for traffic signal systems was performed by the Bavarian Road Administration. This research used anonymized GPS data to calculate measures of vehicle delay near established traffic signals. While this study did consider changes in vehicle delay due to signal timing, signal controller event data was not incorporated in the evaluation process (8).

Based on current research, there exists a significant need for published data and results for specific signal timing improvements, assessed over a much longer period of time than traditional before/after analyses, which tend to focus on only a few weeks of data surrounding an intervention. This study aims to partially fill a gap in the literature on long-term active traffic management, by examining a moderately-congested signalized corridor over a period of 5 years, and looking at how periodic retiming driven by highresolution event data can mitigate degradation in travel times and signal timing performance. The results can help agencies to better understand signal timing in an asset management context, and provide evidence that active long-term monitoring and planning for the maintenance of non-hardware signal assets (such as signal timing plans) can generate significant returns. 


\section{Methodology}

\section{Five-Year Signal Timing Plan Maintenance and High Resolution Data Collection}

State Road (SR) 37, shown in Figure 1, was selected for the longitudinal study, and is actively maintained by the Indiana Department of Transportation (INDOT). In 2012, a new signal was installed at the $135^{\text {th }} \mathrm{Pl}$. intersection, which may account for some of the volume growth. Also during the study period, the interchange at SR37 and I-69 was expanded from having one lane to two lanes in each direction. This improvement eliminated occasional queuing near $126^{\text {th }}$ St., which affected the southbound direction in the AM peak and the northbound direction during the PM peak. Construction was ongoing for most of 2013, and the additional lanes opened in November 2013. While this eliminated some peak period queue spillbacks affecting the south end of the corridor, the added ramp lanes may also have accelerated the growth in corridor traffic volumes over the final years of the analysis period.

The signals used in this analysis are all controlled with NEMA, TS/2 signal controllers, capable of logging high resolution signal controller data. The side streets and mainline left turn movements are controlled using stop bar detection, while the arterial through movements contain advance loop detectors only, set back approximately 400' from the intersection.

Three different offset optimizations were carried out during the analysis period: summer 2010, summer 2013, and summer 2015. Each optimization was performed using high resolution event data and an objective function designed to maximize total arrivals on green. This methodology will be described further in the next section.

For all three offset optimizations, data was gathered separately for weekday and Saturday time-of-day (TOD) plans. For the 2010 and 2013 offset optimizations, approximately three weeks of data before and after the optimization were gathered to generate the relevant performance measures. For the 2015 offset optimization, one week of data was collected before the optimization, and two weeks after the optimization. For the weekday and Saturday time periods, data was collected from 0600 to 1900. Table 1 shows the TOD plans for the weekday and Saturday time periods during which measurements were recorded. A total of five timing plans were considered on weekdays and four timing plans on Saturdays.

\section{Offset Optimization}

Optimization of progression requires an understanding of vehicle arrival characteristics at each signalized approach. It is reasonable to expect that measuring these properties in the field will result in better outcomes than relying on theoretical relationships or idealized assumptions.

High resolution signal controller event data is used to develop a record of phase changes and vehicle detections $(9,10)$. Using this data, one can develop profiles of vehicle arrivals and relate them to the probability of green (11). These flow profiles can serve as a means to predict what will happen if the offsets are adjusted, by displacing the vehicle arrival and green time distributions accordingly (12). For example, an offset adjustment of +10 seconds corresponds to a displacement of the local green times by +10 seconds, and of the downstream arrival profiles by +10 seconds as well. By relating the shift in predicted green times to the vehicle arrival profiles calculated from the signal controller event data, offsets along the corridor can be systematically optimized. 
Numerous objective functions have been considered for optimally setting offsets- common strategies include minimizing total user delay $(13,14)$, or maximizing vehicle arrivals on green. A method for the latter on arterials with high resolution data (15) was initially demonstrated on SR 37 (16), but has also been used at other locations (17).

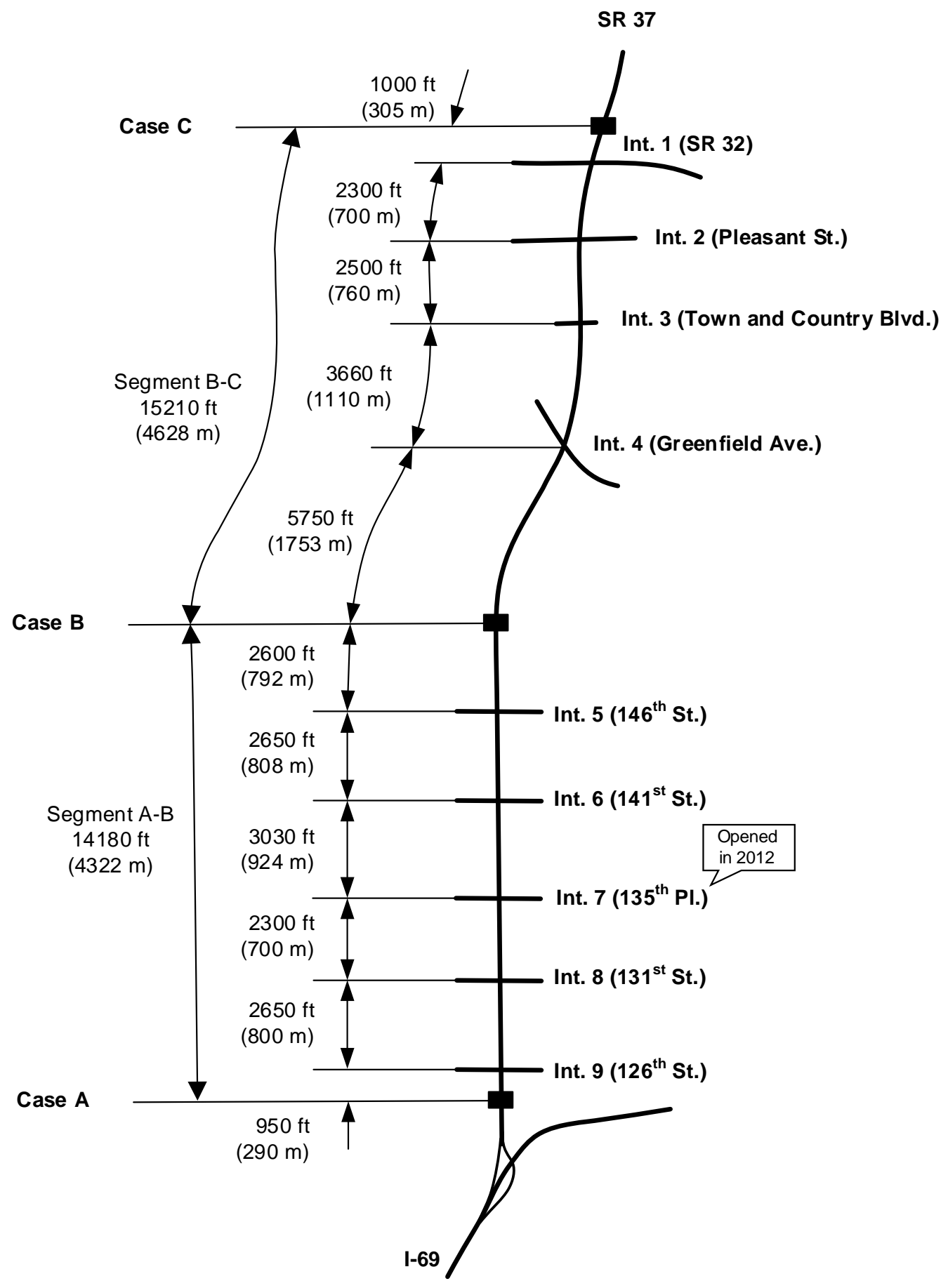

Figure 1 SR37 corridor overview and Bluetooth antenna positioning 
Table 1 SR37 Time-of-Day (TOD) Plan Overview for Weekdays \& Saturdays

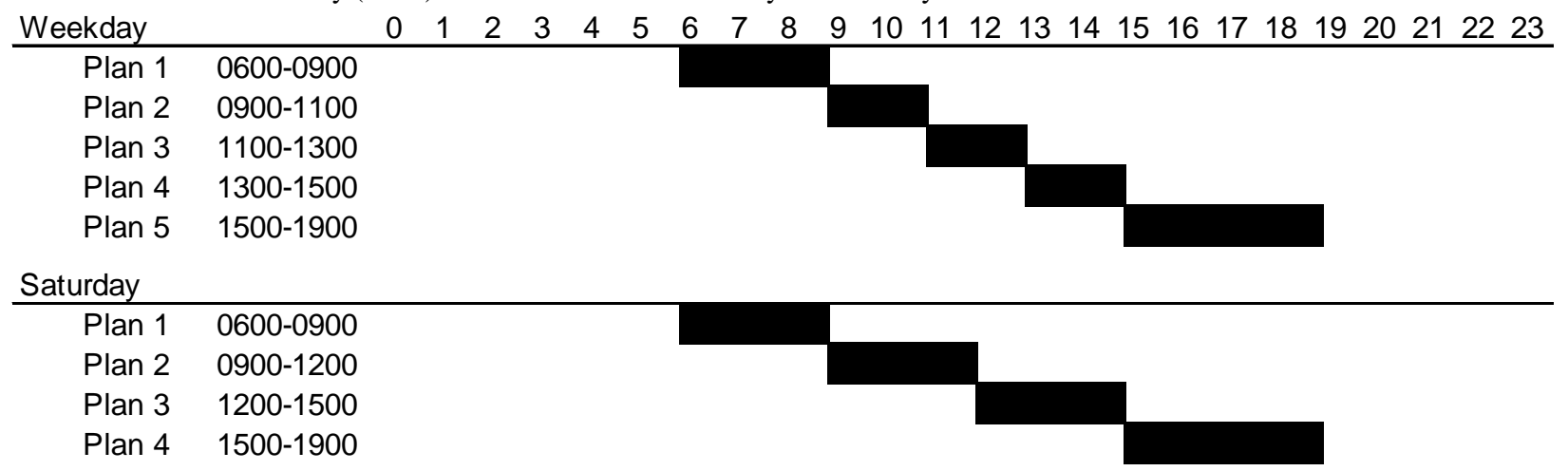

\section{Travel Time Measurement}

Bluetooth Media Access Control (MAC) address matching was utilized to estimate travel times before and after each optimization (18). This methodology is significantly more robust than traditional pilot car studies, and the number of observed travel times over the analysis period represented approximately 5\% of the total traffic volume. Outlier travel times, defined as 1.5 times above or below the interquartile range (IQR, the difference between the $25^{\text {th }}$ and $75^{\text {th }}$ percentiles for the observed data), were removed to eliminate errors from incorrect matching, and to account for intermediate detours/stops made by drivers, which could bias the results.

Figure 1 shows the location of Bluetooth data collection devices along the SR37 corridor. Three locations were used for the devices - Case A and Case C established cordon points at the southern and northern ends of the corridor, respectively, while Case B served as a dividing point, from which sub-corridor travel times could be computed. This was beneficial for the step of computing total user benefits from retiming; because relatively few drivers traverse the entire SR37 corridor, a more accurate estimation of corridorlevel benefits was determined by summing the benefits on sub-corridor segments A-B and B-C.

The collection of such detailed travel time data, compared to historical means, has given agencies the ability to generate more comprehensive travel time performance measures $(19,20)$. One increasinglycommon measure is that of a travel time distribution function (21). Figure 2 shows how individually measured travel times are converted into cumulative distribution functions (CDFs) for the purposes of assessing changes before and after an intervention (in this case, a signal offset optimization). Part $a$ shows the individual observed travel times, herein measured using the Bluetooth devices. In this example, the travel times are measured from device A to device C for Saturdays in 2013, from 1500-1900. Part $b$ shows a histogram of the travel times before the offset optimization. Travel times vary from 5 minutes to 15 minutes, with the majority in the 7- to 9- minute range. These travel times can be turned into a CDF to better characterize the overall distribution. Here, the median $\left(50^{\text {th }}\right.$ percentile) travel time is approximately 8.5 minutes, as denoted by callout $i$. Callout $i$ shows the IQR, the distance between the $25^{\text {th }}$ and $75^{\text {th }}$ percentiles, which is approximately 2 minutes. 

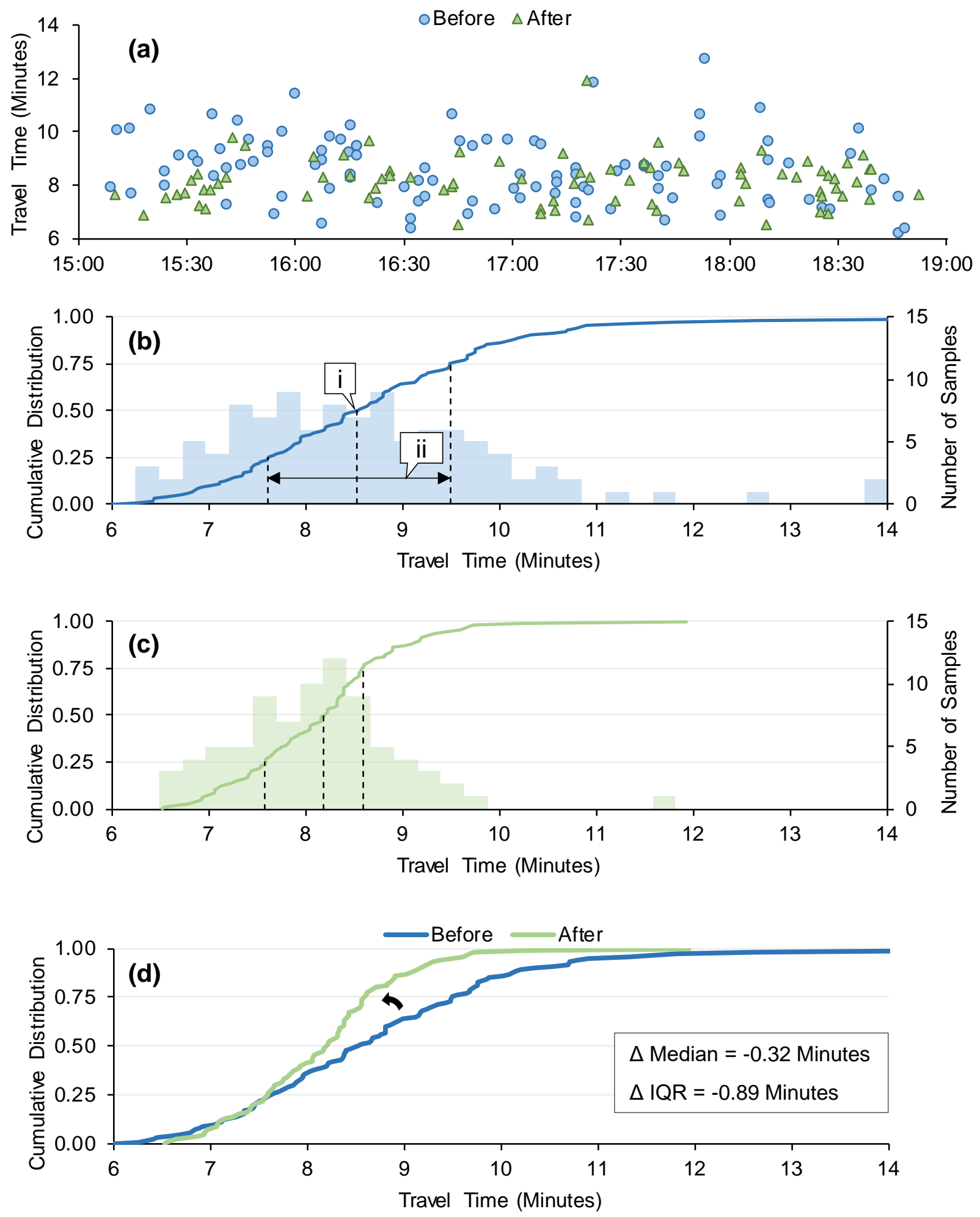

Figure 2 Comparison of travel times using cumulative distribution functions (CDFs) before/after offset optimization: (a) Observed travel times (2013 NB segment A-C, 1500 - 1900); (b) Histogram and CDF of "before” travel times; (c) Histogram and CDF of "after" travel times; (d) Combined travel time CDFs, with summary statistics 
Likewise, part $c$ of Figure 2 shows a histogram and corresponding CDF for the travel times after offset optimization. Here, the median travel time is slightly more than 8 minutes, and nearly all observed travel times are 9.5 minutes or less.

Part $d$ shows an overlay of travel time CDFs before and after offset optimization. Note the leftward shift in the CDF after optimization. The median travel time decreases by 0.32 minutes (approximately 19 seconds), while the travel time IQR decreases by 0.89 minutes (approximately 53 seconds). Also note how the post-optimization CDF appears to rotate counterclockwise, relative to the pre-optimization CDF. Correspondingly, a greater improvement in travel times for the upper end of the post-optimization distribution is seen than for the lower end, and generally results in a steeper slope for the postoptimization CDF. This steeper slope indicates an improvement in travel time reliability. That is, drivers, on average, are experiencing more consistent travel times after optimization, irrespective of any improvements made in the average travel times.

\section{Outcome Assessment}

To assess the impact of optimization, we consider performance measures based on high resolution data and travel time data. Signal-based performance measures include changes in total arrivals on green (AOG) and percent arrivals on green (POG). These quantify the number or proportion of vehicles successfully progressed through the signalized approaches, as determined by comparing the detected arrival time with the concurrent status of green. The calculation of this performance measure has been documented previously (22).

The median travel times, along with the IQR for each CDF, were assessed to determine potential gains and losses in the system with each optimization. In estimating user travel time benefits that result from the post-optimization scenarios, we incorporate both the monetary value of travel time savings and the value of improvements in reliability. The measure for travel time reliability was chosen to be the standard deviation of travel time through the corridor, in line with previously established methodology (23), (24). The travel time benefits for passenger and commercial vehicles are computed as:

$$
\text { Benefit }_{i}=\operatorname{TTSV}_{i}+\operatorname{TTRV}_{i}
$$

Where

$$
\begin{aligned}
& \text { Benefit }_{i}=\text { total travel time benefits for vehicle type } i(\$) \\
& \operatorname{TTSV}_{i}=\text { travel time savings value for vehicle type } i(\$) \\
& T T R V_{i}=\text { travel time reliability value for vehicle type } i(\$)
\end{aligned}
$$

And

$$
\begin{aligned}
& \operatorname{TTSV}_{i}=\Delta T T * V o l * P_{i} * O c c_{i} * T T V_{i} * 1 \mathrm{hr} / 60 \mathrm{~min} \\
& T T R V_{i}=\Delta S D * V o l * P_{i} * O c c_{i} * S D V_{i} * 1 \mathrm{hr} / 60 \mathrm{~min}
\end{aligned}
$$

Here,

$\Delta T T=$ The change in mean travel time along the corridor, as measured using the Bluetooth data (min) 
$\Delta S D=$ The change in the standard deviation of travel time along the corridor (min)

$\mathrm{Vol}=$ The traffic volume through the corridor during the analysis period, measured using count detectors on the intersection approaches (vehicles)

$P_{i}=$ The percentage of the traffic stream that vehicle type $i$ comprises

$O c c_{i}=$ The average vehicle occupancy of vehicle type $i$ (persons)

$\operatorname{TTV}_{i}=$ The time value of money for an individual in vehicle type $i$ (\$/person-hr)

$S D V_{i}=$ The monetary value of a unit change in travel time standard deviation for an individual in vehicle type $i$ (\$/person-hr)

In this analysis, two vehicle types were considered: passenger cars and commercial trucks. The value of travel time was drawn from the 2011 version of the Urban Mobility Report (25), and updated to 2015 values using the Consumer Price Index (CPI). For additional details on the theory behind specific travel time and travel time reliability calculations, refer to Li et al. (17). 


\section{Assessment of Signal Timing Over Five Years}

\section{Signal Performance Measures}

Figure 3 through Figure 6 demonstrate the impacts and benefits of active maintenance of the signal timing plans over the 5-year period. Numerous improvements were seen in all categories of performance measures, especially in 2010, as one might expect due to the absence of a prior data-driven retiming strategy.

At the same time, it is also important to note that changes in travel time as a result of offset optimizations were not universally positive. Figure 3 illustrates these differences. Part $a, c$, and $e$ show improvements in travel time and travel time reliability for both the northbound and southbound directions, for the 15001900 TOD plan on Saturdays in 2013. Similarly, parts $b, d$, and $f$ show that for northbound traffic, travel time and travel time reliability improved post- optimization, for the 1200-1500 TOD plan on Saturdays in 2015. However, southbound travel times here actually worsened, with a 0.26 -minute increase in median travel time, and a 1.87-minute increase in travel time IQR. This tradeoff reflects the fact that during offset optimization (and signal timing in general), one is often forced to make a choice between two conflicting demands. Often progression improvements for one direction at an intersection can only be made at the expense of the opposing direction. In such cases, the benefit of the decision must be considered in terms of the total system impact, such as by calculating the cumulative user benefit. Although an individual route might experience some degradation, the overall system benefit may still be positive.

Figure 4 shows the change in AOG and POG for each direction on SR37, as a result of the offset optimizations in 2010, 2013, and 2015. In parts $a$ and $b$, AOG is broken out by direction, while AOR is shown for northbound and southbound combined. This provides excellent context for the need to consider long-term active traffic management strategies. During each optimization period, AOG and POG usually increased. One exception is a decrease in AOG in 2015, which coincides with a decrease in volume within the before and after periods. There are also some interesting dynamics between years as well. For example, AOG and POG appear to have increased between 2010 and 2013, which may be a function of arterial traffic volumes growing at a faster pace than side street volumes during that time period. However, AOG and POG decreased between 2013 and 2015.

In part $a$, it can be seen that total arrivals for Saturdays, by intersection, increased from approximately 20,000 in 2010 to 25,000 in 2015, a change of 25\%. Likewise, part $b$ shows that total arrivals per weekday, by intersection, increased from approximately 25,000 in 2010 to 29,000 in 2015, a change of $16 \%$. Despite the significant increase in traffic volumes, the growth in AOG actually outpaced the growth in total arrivals, increasing by 46\% between 2010 and 2015 for Saturdays, and by 28\% between 2010 and 2015 for weekdays. This is due in large part to the ongoing and repeated optimization of progression along the corridor. 

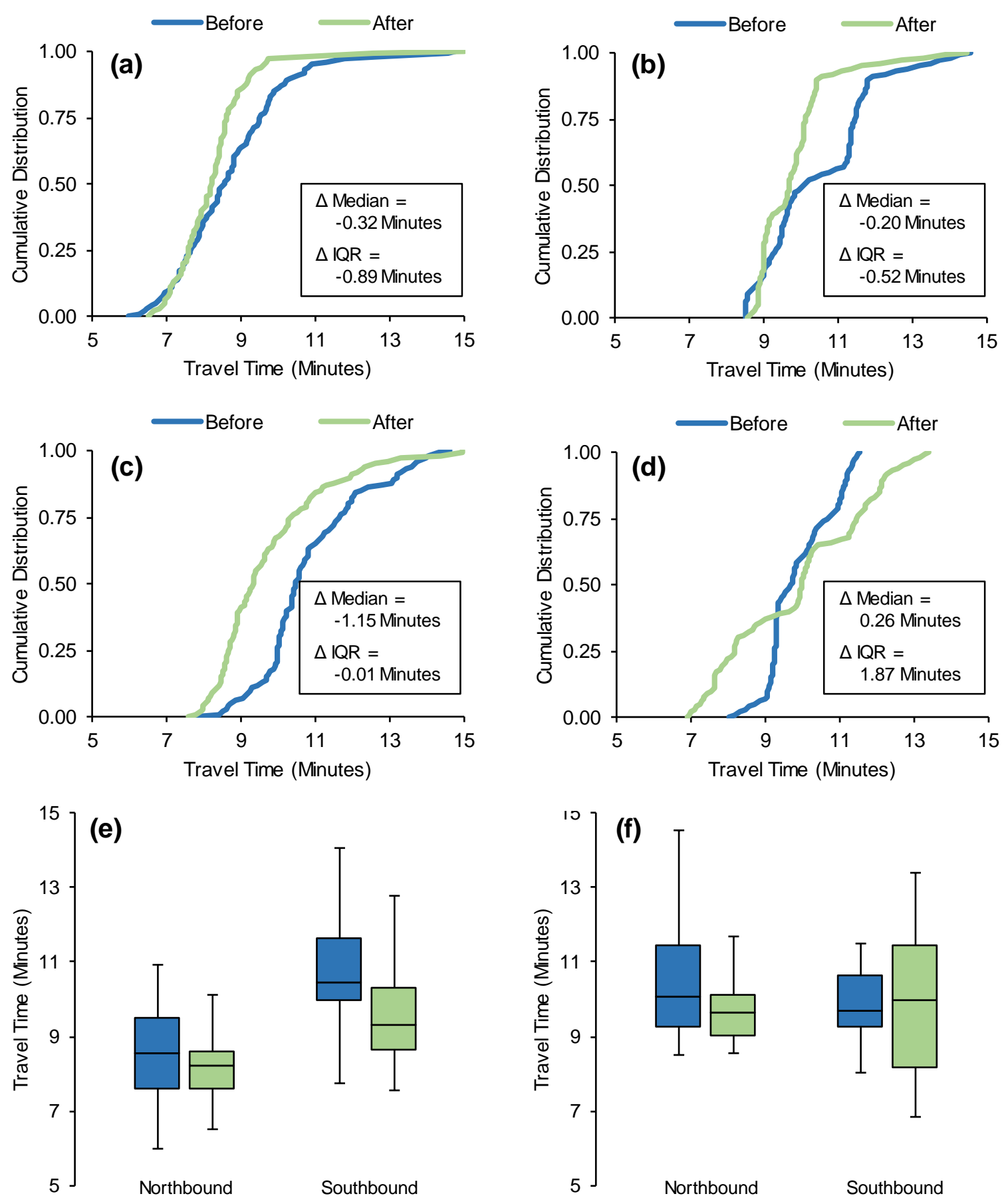

Figure 3 Comparison of offset optimization outcomes. (a)/(c)/ (e) demonstrate northbound and southbound travel time improvements, while (b)/(d)/(f) show northbound improvements at the expense of southbound vehicles
(a) Northbound before/after travel time CDFs, 2013, TOD plan 1500-1900
(b) Northbound before/after travel time CDFs, 2015, TOD plan 1200-1500
(c) Southbound before/after travel time CDFs, 2013, TOD plan 1500-1900
(d) Southbound before/after travel time CDFs, 2015, TOD plan 1200-1500
(e) Northbound and southbound before/after travel time box-whisker plots, 2013, TOD plan 1500-1900
(f) Northbound and southbound before/after travel time box-whisker plots, 2015, TOD plan 1200-1500 
(a) Saturdays

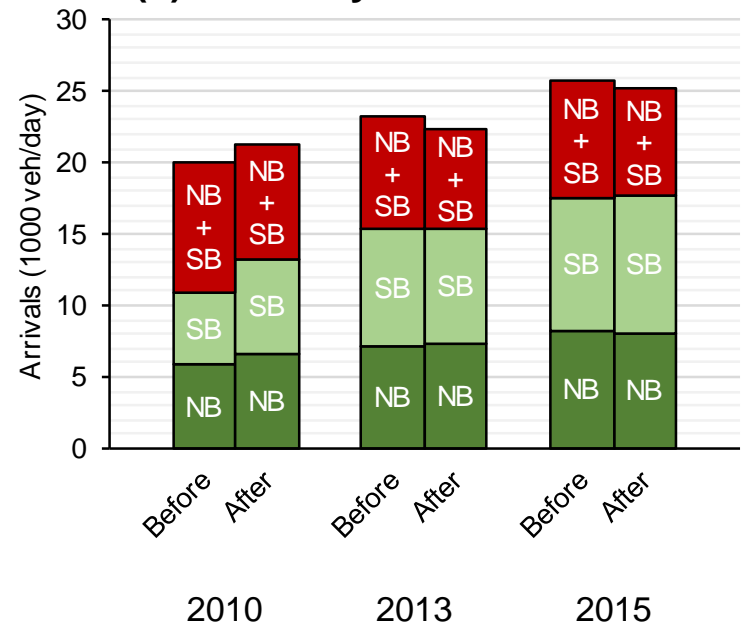

\section{(c) Saturdays}

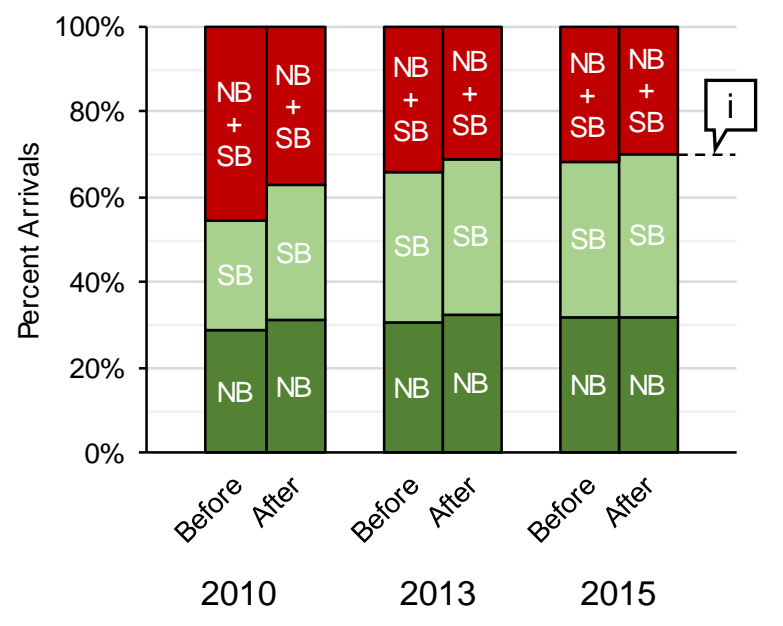

(b) Weekdays

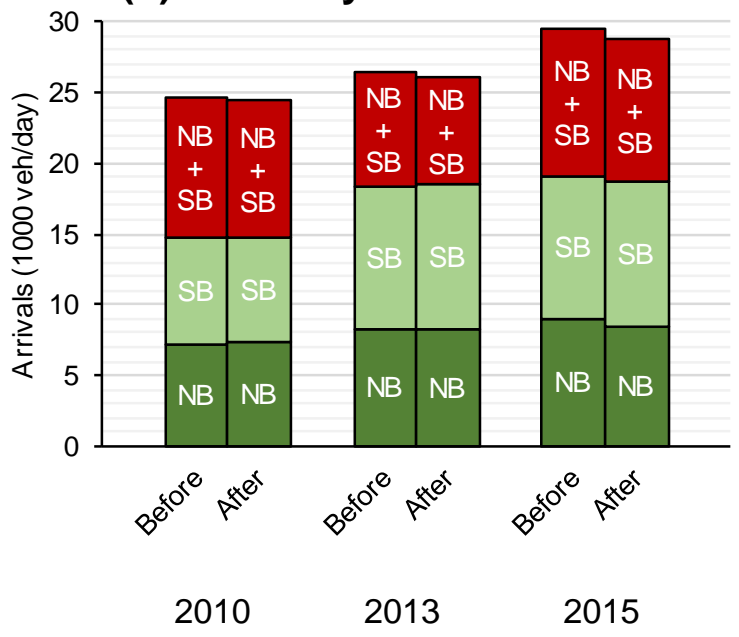

(d) Weekdays

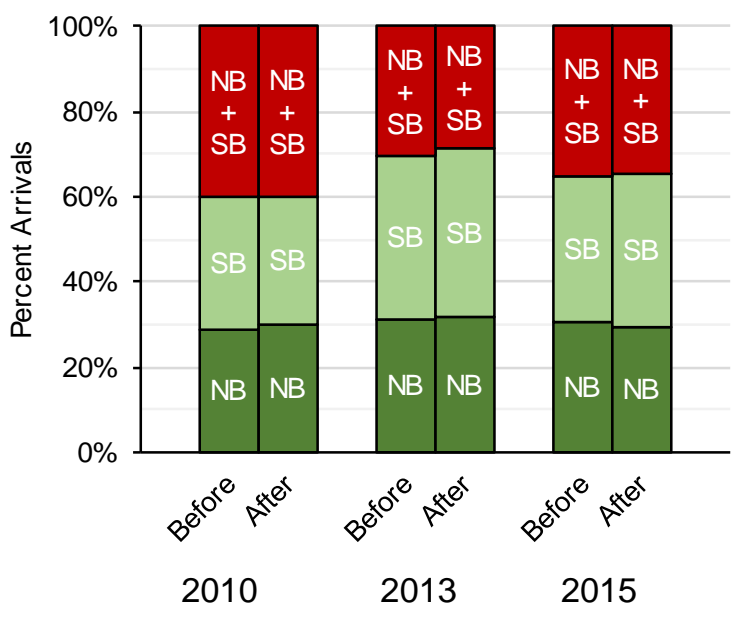

Arrivals on Red, Both Directions

Arrivals on Green, Southbound

Arrivals on Green, Northbound

Figure 4 Comparison of arrivals on green (AOG) and percent arrivals on green (POG) for weekdays and Saturdays from 06001900, before/after offset optimization

(a) Average AOG and combined northbound/southbound arrivals on red (AOR), per intersection, Saturdays

(b) Average AOG and combined northbound/southbound arrivals on red (AOR), per intersection, weekdays

(c) Average POG and combined northbound/southbound percent arrivals on red (POR), per intersection, Saturdays

(d) Average POG and combined northbound/southbound percent arrivals on red (POR), per intersection, weekdays 
In part $c$ and $d$ of Figure 4, POG is the sum of the northbound and southbound percent arrivals. For example, for Saturdays in 2015, post-optimization, northbound AOG comprised approximately 31\% of all arrivals, while southbound AOG comprised approximately 39\% of all arrivals. Callout $i$ shows that total POG for this scenario was the sum of these two percentages, or $70 \%$. The figures here demonstrate moderate growth in POG between 2010 and 2015. For Saturdays, POG increased from 59\% to 69\%, a $10 \%$ increase (17\% improvement over the initial value of POG). Likewise, weekday POG increased from $60 \%$ to $65 \%$, a $5 \%$ increase ( $8 \%$ improvement). For part $c$, on average, Saturday offset optimizations resulted in $4 \%$ higher POG (8\% improvement) and in part $d$, on average, weekday offset improvements resulted in an increase of $1 \%$ ( $2 \%$ improvement).

With offset optimization and mainline signal timing improvements, one must also be cognizant of the needs of side street traffic and potentially worsening driver delay. Improvements can always be made to progression on the mainline by simply increasing green time, but this strategy increases delay for drivers on the minor approaches. Figure 5 demonstrates for both Saturdays (part $a$ ) and weekdays (part $b$ ), despite the growth in arterial AOG and POG, the total green time given to the northbound and southbound mainline movements was not significantly increased. The green time totals exclude the $135^{\text {th }}$ St. intersection, which was not present when the 2010 offset optimizations were performed, to avoid distorting the comparison.

(a)

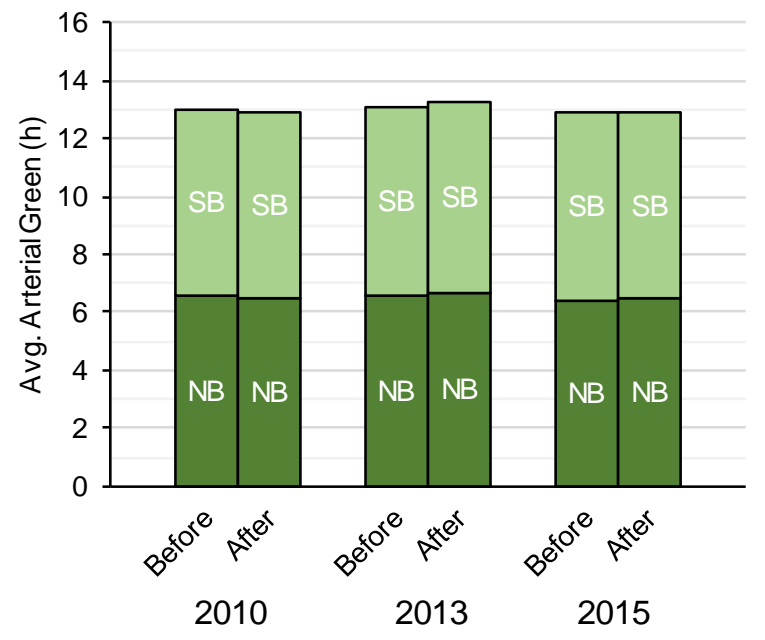

(b)

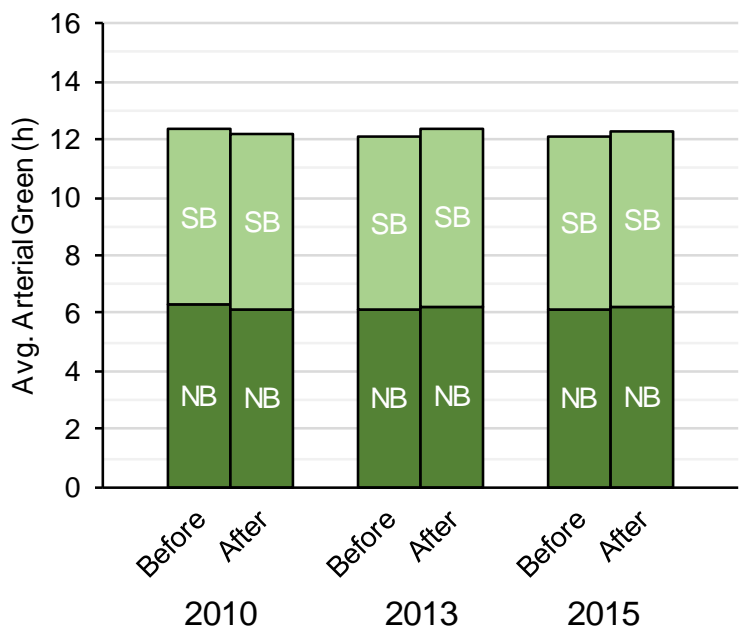

Figure 5 Comparison of arterial green time, excluding 135th St., for weekdays and Saturdays from 0600-1900, before/after offset optimization

(a) Average northbound/southbound arterial green time, per intersection, Saturdays

(b) Average northbound/southbound arterial green time, per intersection, weekdays

\section{Travel Time and Travel Time Reliability Impacts}

Figure 6 shows the change in annualized user travel time and travel time reliability costs with each offset optimization. In parts $a$ and $b$, it can be seen that the year-over-year growth in travel time costs largely mirrors the growth in traffic volumes along the corridor. For part $a$, Saturday travel time and reliability costs increased by approximately 22\% between 2010 and 2015. For part $b$, weekday travel time and reliability costs increased by approximately 38\% between 2010 and 2015. 
(a)

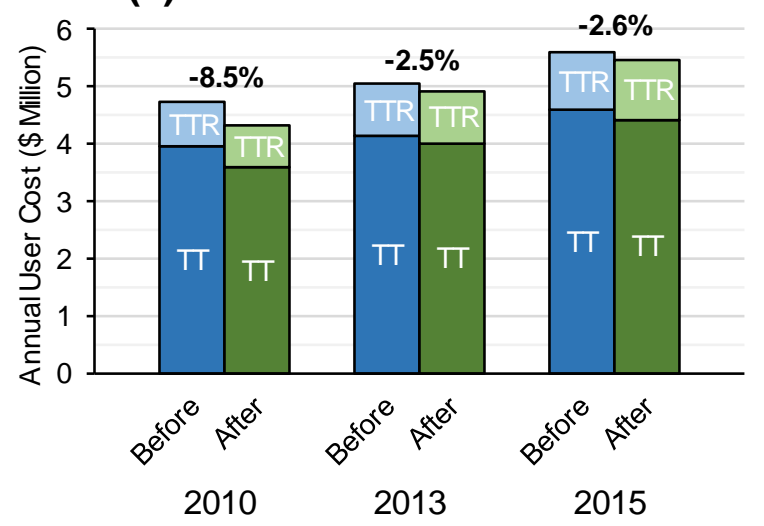

(c)

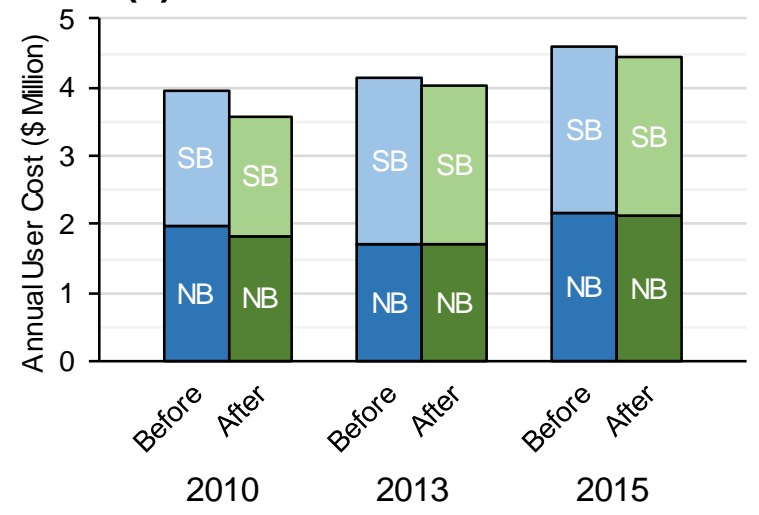

(e)

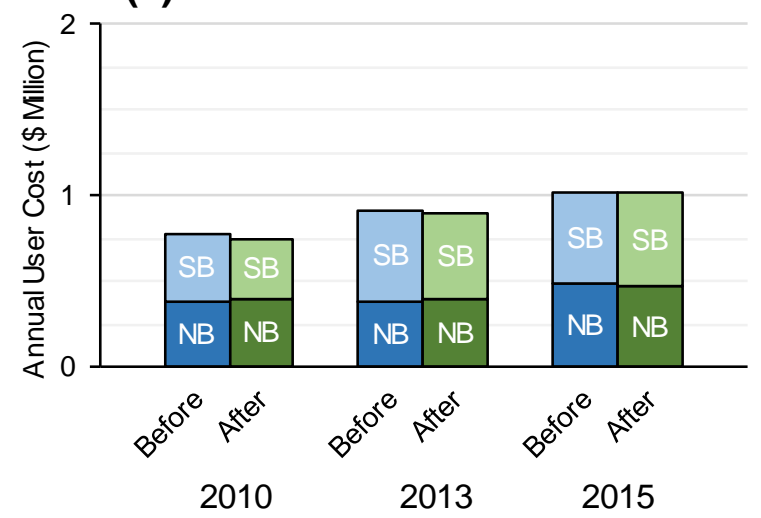

(b)

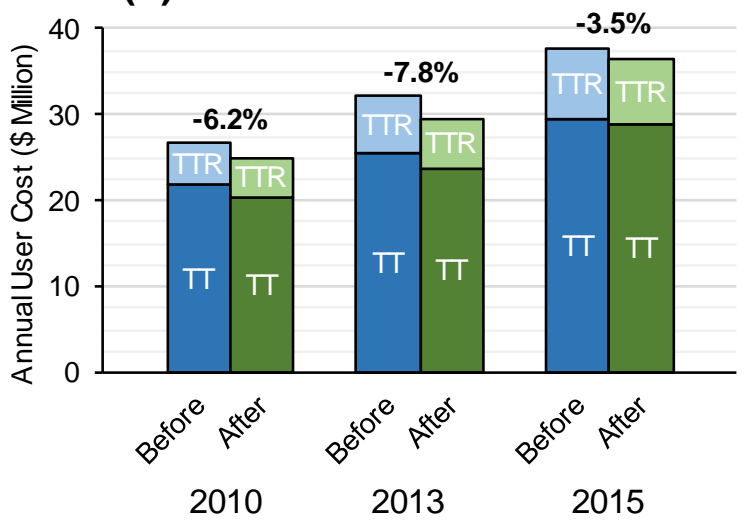

(d)

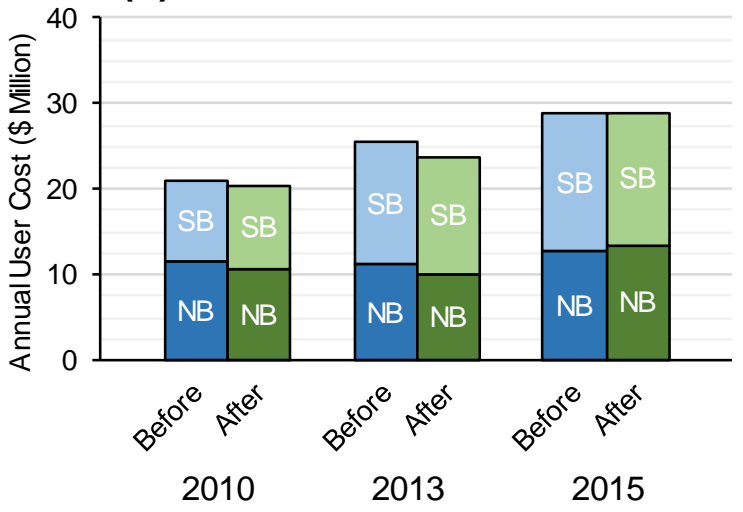

(f)

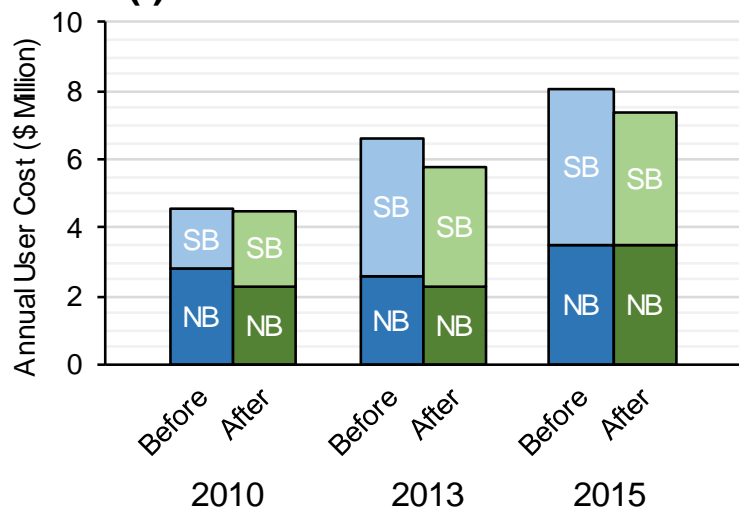

Figure 6 Annual travel time (TT) and travel time reliability (TTR) costs for weekdays and Saturdays, from 0600-1900, before/after offset optimization

(a) Combined annual northbound/southbound TT and TTR costs, Saturdays

(b) Combined annual northbound/southbound TT and TTR costs, weekdays

(c) Annual northbound/southbound TT costs, Saturdays

(d) Annual northbound/southbound TT costs, weekdays

(e) Annual northbound/southbound TTR costs, Saturdays

(f) Annual northbound/southbound TTR costs, weekdays 
Despite the increase in traffic volumes and the travel time and reliability costs, a substantial user benefit was borne out by all three offset optimizations. For example, in 2010, the optimization resulted in an 8.5\% decrease in total user cost for Saturdays, while 2015 optimization realized a 2.6\% decrease in user cost. On average, total user costs decreased by $4.5 \%$ each time an offset optimization was performed, compared to annualized pre-optimization user costs. Weekday improvements were similarly substantial. On average, total user costs decreased by $6 \%$ each time an offset optimization was performed.

It can also be seen that specific time periods saw variable magnitudes of improvement in travel time and travel time reliability. Parts $c$ and $d$ of Figure 6 demonstrate the changes in annualized travel time costs only, for Saturdays and weekdays, respectively. In parts $e$ and $f$, changes in annualized travel time reliability costs for Saturdays and weekdays, respectively, are shown. Generally, it appears that for Saturdays, most of the user benefit was derived from improvements in average travel times (part $c$ ); there is little to no change in travel time reliability costs before and after offset optimization (part $e$ ). In contrast, for weekday time periods, in addition to benefits due to travel time improvements (part $d$ ), significant user benefit was realized due to travel time reliability improvements (part $f$ ). For example, in 2013, annualized travel time reliability costs fell from $\$ 6.7$ million to $\$ 5.9$ million, a decrease of $14 \%$.

Table 2 and Table 3 show the total user benefits due to offset optimization for all TOD plans and directions, for Saturday and weekday time periods, respectively. In total, offset optimizations during this 5-year time period resulted in a cumulative user benefit of approximately \$3.6 million. The costs are also shown in per-vehicle terms, which are computed by dividing the change in user costs for each year by the volume per direction within that year. The magnitude of the changes is decreasing by year, which can be explained partly by the increasing traffic volume, as well as the decreasing extent of the signal timing changes. That is, in 2010, the first year that the optimization technique was used, there were substantial changes, but in subsequent years the changes were less drastic. 
Table 2 Annual TT and TTR user benefits from offset optimization, Saturdays from 0600-1900

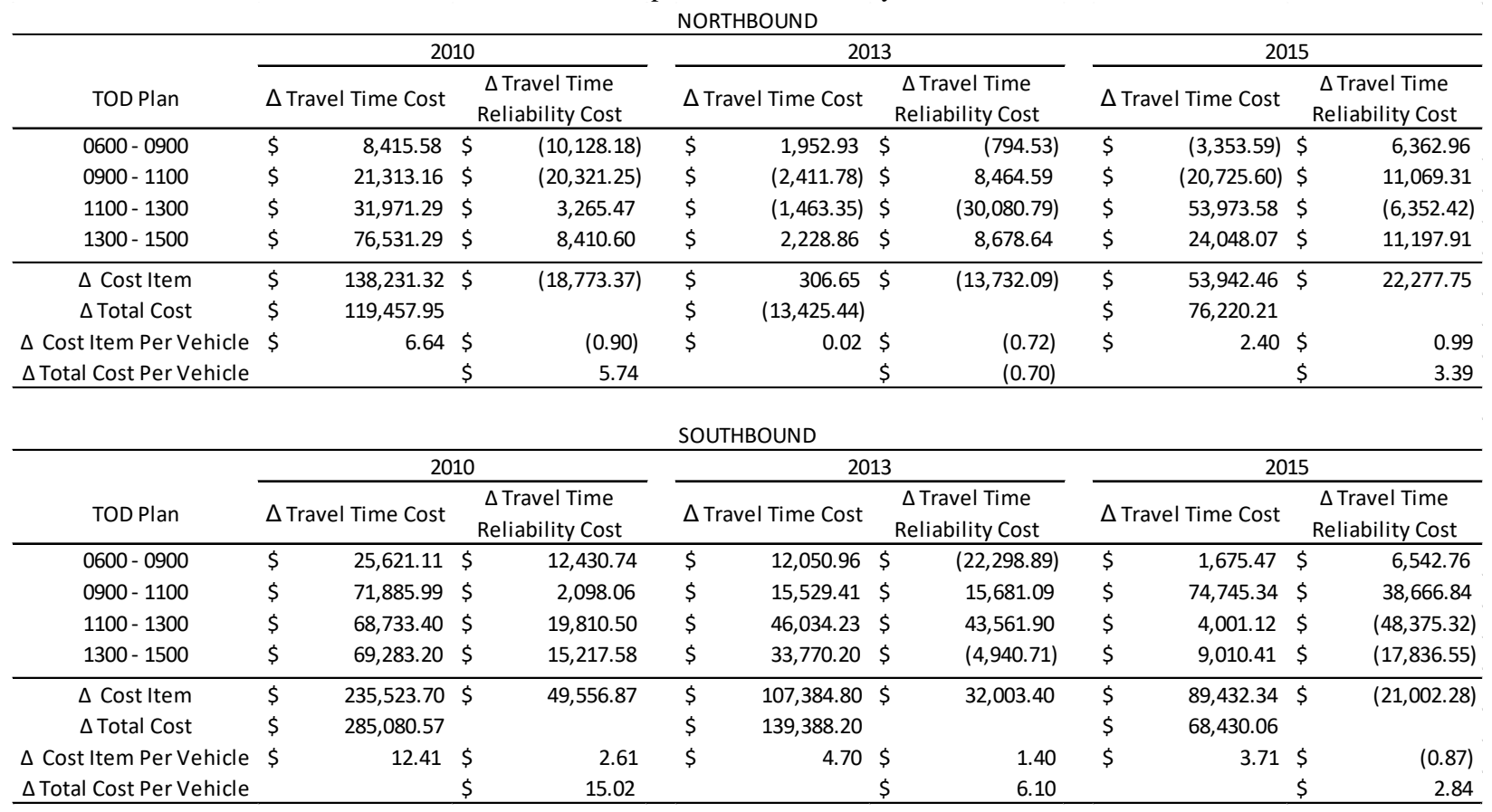


Table 3 Annual TT and TTR user benefits from offset optimization, weekdays from 0600-1900

\begin{tabular}{|c|c|c|c|c|c|c|c|c|c|c|c|c|}
\hline \multirow{4}{*}{$\begin{array}{c}\text { TOD Plan } \\
0600-0900\end{array}$} & \multicolumn{8}{|c|}{ NORTHBOUND } & \multirow{2}{*}{\multicolumn{4}{|c|}{2015}} \\
\hline & \multicolumn{4}{|c|}{2010} & \multicolumn{4}{|c|}{2013} & & & & \\
\hline & \multicolumn{2}{|c|}{$\Delta$ Travel Time Cost } & \multicolumn{2}{|c|}{$\begin{array}{c}\Delta \text { Travel Time } \\
\text { Reliability Cost }\end{array}$} & \multicolumn{2}{|c|}{$\Delta$ Travel Time Cost } & \multicolumn{2}{|c|}{$\begin{array}{c}\Delta \text { Travel Time } \\
\text { Reliability Cost }\end{array}$} & \multicolumn{2}{|c|}{$\Delta$ Travel Time Cost } & \multicolumn{2}{|c|}{$\begin{array}{c}\Delta \text { Travel Time } \\
\text { Reliability Cost }\end{array}$} \\
\hline & $\$$ & $142,577.06$ & $\$$ & $5,618.36$ & $\$$ & $143,214.37$ & $\$$ & $40,520.98$ & $\$$ & $(102,789.03)$ & $\$$ & $30,823.53$ \\
\hline $0900-1100$ & $\$$ & $144,873.12$ & $\$$ & $79,591.87$ & $\$$ & $33,513.72$ & $\$$ & $47,637.04$ & $\$$ & $(89,166.30)$ & $\$$ & $10,003.29$ \\
\hline $1100-1300$ & $\$$ & $221,599.60$ & $\$$ & $79,306.10$ & $\$$ & $(39,587.18)$ & $\$$ & $(93,911.93)$ & $\$$ & $(196,196.18)$ & $\$$ & $21,843.44$ \\
\hline $1300-1500$ & $\$$ & $160,104.68$ & $\$$ & $61,866.53$ & $\$$ & $136,254.62$ & $\$$ & $104,544.28$ & $\$$ & $(213,871.17)$ & $\$$ & $(5,855.49)$ \\
\hline $1500-1900$ & $\$$ & $314,851.65$ & $\$$ & $272,326.97$ & $\$$ & $688,192.46$ & $\$$ & $178,590.71$ & $\$$ & $(197,886.53)$ & $\$$ & $(67,667.44)$ \\
\hline$\Delta$ Cost Item & $\$$ & $984,006.12$ & $\$$ & $498,709.83$ & $\$$ & $961,587.99$ & $\$$ & $277,381.08$ & $\$$ & $(799,909.22)$ & $\$$ & $(10,852.66)$ \\
\hline$\Delta$ Total Cost & $\$$ & $1,482,715.94$ & & & $\$$ & $1,238,969.07$ & & & $\$$ & $(810,761.88)$ & & \\
\hline$\Delta$ Cost Item Per Vehicle & $\$$ & 43.53 & $\$$ & 22.06 & $\$$ & 43.91 & $\$$ & 12.67 & $\$$ & $(33.02)$ & $\$$ & $(0.45)$ \\
\hline$\Delta$ Total Cost Per Vehicle & & & $\$$ & 65.59 & & & $\$$ & 56.57 & & & $\$$ & $(33.46)$ \\
\hline \multicolumn{13}{|c|}{ SOUTHBOUND } \\
\hline & \multicolumn{4}{|c|}{2010} & \multicolumn{4}{|c|}{2013} & \multicolumn{4}{|c|}{2015} \\
\hline TOD Plan & \multicolumn{2}{|c|}{$\Delta$ Travel Time Cost } & \multicolumn{2}{|c|}{$\begin{array}{c}\Delta \text { Travel Time } \\
\text { Reliability Cost }\end{array}$} & \multicolumn{2}{|c|}{$\Delta$ Travel Time Cost } & \multicolumn{2}{|c|}{$\begin{array}{c}\Delta \text { Travel Time } \\
\text { Reliability Cost }\end{array}$} & \multicolumn{2}{|c|}{$\Delta$ Travel Time Cost } & \multicolumn{2}{|c|}{$\begin{array}{c}\Delta \text { Travel Time } \\
\text { Reliability Cost }\end{array}$} \\
\hline $0600-0900$ & $\$$ & $63,852.99$ & $\$$ & $(11,173.80)$ & $\$$ & $139,007.59$ & $\$$ & $86,140.98$ & $\$$ & $522,782.11$ & $\$$ & $640,498.11$ \\
\hline $0900-1100$ & $\$$ & $(127,390.54)$ & $\$$ & $(96,595.28)$ & $\$$ & $64,897.14$ & $\$$ & $46,055.57$ & $\$$ & $30,402.47$ & $\$$ & $(73,496.44)$ \\
\hline $1100-1300$ & $\$$ & $(85,704.08)$ & $\$$ & $26,693.28$ & $\$$ & $(84,459.96)$ & $\$$ & $(16,493.21)$ & $\$$ & $(175,879.37)$ & $\$$ & $(118,710.36)$ \\
\hline $1300-1500$ & $\$$ & $(76,747.51)$ & $\$$ & $(69,275.94)$ & $\$$ & $(253,692.02)$ & $\$$ & $42,813.36$ & $\$$ & $111,148.81$ & $\$$ & $74,051.44$ \\
\hline $1500-1900$ & $\$$ & $(245,039.78)$ & $\$$ & $(327,425.21)$ & $\$$ & $818,646.80$ & $\$$ & $430,469.40$ & $\$$ & $148,734.72$ & $\$$ & $171,536.03$ \\
\hline$\Delta$ Cost Item & $\$$ & $(471,028.91)$ & $\$$ & $(477,776.96)$ & $\$$ & $684,399.54$ & $\$$ & $588,986.09$ & $\$$ & $637,188.73$ & $\$$ & $693,878.79$ \\
\hline$\Delta$ Total Cost & $\$$ & $(948,805.87)$ & & & $\$$ & $1,273,385.64$ & & & $\$$ & $1,331,067.53$ & & \\
\hline$\Delta$ Cost Item Per Vehicle & $\$$ & (23.31) & $\$$ & (23.64) & $\$$ & 26.96 & $\$$ & 23.20 & $\$$ & 23.52 & $\$$ & 25.61 \\
\hline$\Delta$ Total Cost Per Vehicle & & & $\$$ & $(46.95)$ & & & $\$$ & 50.16 & & & $\$$ & 49.13 \\
\hline
\end{tabular}




\section{Conclusions}

The results of this study demonstrate that for corridors with moderate traffic growth, without intervention, timing plans and travel times show marked deterioration over a period of just a few years. This presents a challenge to many public agencies, who continue to retime traffic signals on an imprecise schedule, or rely on limited feedback, such as public complaint calls. As a cost-effective alternative, this paper demonstrates that high resolution signal controller data, periodic travel time assessment with reidentification technologies, and associated performance measures can be used to actively monitor longterm degradation of traffic conditions, and make better informed decisions about when to undertake retiming. Outcome assessment by travel time measurement allows a positive impact to be independently confirmed.

Generally, it was found that by adopting active traffic management strategies supported with high resolution event data, agencies can derive substantial user benefit by periodically revisiting and retiming corridors, at least biennially, and perhaps annually. A summary of routine optimization and specific impact is shown below:

- 3 different offset optimizations were carried out on a moderately-congested signalized corridor over a 5-year period.

- Total intersection arrivals increased approximately 36\% between 2010 and 2015 (or 6\% annually). During this time, an additional intersection and several new lanes were constructed on the south end of the study corridor.

- AOG along the corridor outpaced the growth in overall volumes increasing by $41 \%$.

- POG increased by $12.1 \%$ (8 percentage points) over the 5-year period for weekdays and by approximately $8.8 \%$ (5 percentage points) for weekends.

- Average travel times along the corridor closely matched the growth rate of total traffic volumes, although for all three offset optimizations, net user travel time and travel time reliability costs decreased by approximately 5\%. Total benefits over the 5-year period due to retiming amounted to approximately \$3.6 million.

This research demonstrates that without active management, signal timing and traffic performance can degrade considerably, similar to physical infrastructure assets. It also shows that by using performance measures to actively manage a corridor, agencies can have measureable impact. The after action outcome assessment is particularly important to demonstrate to decision makers the impact their investments have. Embracing performance-based management and outcome assessment is consistent with MAP-21 principles. Agencies that incorporate these methods into their management practices would be better positioned for long term system investments, by being able not only to cite one-time benefits from a before/after perspective, but to additionally quantify the benefits of continuing efforts. 


\section{Acknowledgments}

This work was supported by USDOT SBIR project (contract number DTFH61-14-C-00035) through Traffax, Inc. and Purdue University. The contents of this paper reflect the views of the authors, who are responsible for the facts and the accuracy of the data presented herein, and do not necessarily reflect the official views or policies of the sponsoring organizations. These contents do not constitute a standard, specification, or regulation.

\section{References}

1. Gordon, R. L. NCHRP Synthesis 409: Traffic Signal Retiming Practices in the United States. Washington, D.C., 2010.

2. Cambridge Systematics. Signal Systems Asset Management: State-of-the-Practice Review. Federal Highway Administration, Washington, D.C., Technical Memorandum FHWA-OP04-020, April 2004. http://ops.fhwa.dot.gov/publications/ssam_sop/maintext.htm.

3. Day, C. M., S. M. Remias, H. Li, M. Mekker, M. McNamara, E. Cox, and D. M. Bullock. Performance Ranking of Arterial Corridors Using Travel Time and Travel Time Reliability Metrics. Transportation Research Record: Journal of the Transportation Research Board, 2016.

4. List, G. F. Establishing Monitoring Programs for Travel Time Reliability. SHRP2, Transportation Research Board, Washington, D.C., S2-L02-RR-1, 2014.

5. Isukapati, I. K., G. F. List, S. Eisenman, J. Wojtowicz, and W. Wallace. Analyses of Arterial Travel Times Based on Probe Data, in Advances in Dynamic Network Modeling in Complex Transportation Systems, 2nd ed., Ukkusuri, S., and K. Ozbay. New York: Springer, 2013, pp. 115-142.

6. Liu, H., H. van Lint, and H. van Zuylen. An Investigation of Urban Arterial Travel Time Reliability, in Advanced OR and AI Methods in Transportation, Jaszkiewicz, A., M. Kaczmarek, J. Zak, and M. Kubiak.: Poznan University of Technology, 2005, pp. 528-533.

7. Stevanovic, A., C. Kergaye, and J. Stevanovic. Long-Term Benefits of Adaptive Control Under Varying Traffic Flows During Weekday Peak Hours. Transportation Research Record: Journal of the Transportation Research Board, no. 2311, 2012, pp. 99-107.

8. Wünsch, G., F. Bölling, A. von Dobschütz, and P. Mieth. Bavarian Road Administration uses Probe Data for Large-Scale Traffic Signal Evaluation Support. in TRB 94th Annual Meeting Compendium of Papers , Washington, D.C., 2015.

9. Smaglik, E. J., A. Sharma, D. M. Bullock, J. R. Sturdevant, and G. Duncan. Event-Based Data Collection for Generating Actuated Controller Performance Measures. Transportation Research Record: Journal of the Transportation Research Board, no. 2035, 2007, pp. 97106.

10. Sturdevant, J. R., T. Overman, E. Raamot, R. Deer, D. Miller, D. M. Bullock, C. M. Day, T. M. Brennan, H. Li, A. Hainen, and S. M. Remias. Indiana Traffic Signal Hi Resolution Data Logger Enumerations. Purdue University, West Lafayette, IN, Monograph 2012.

11. Hillier, J., and R. Rothery. The syncronization of traffic signals for minimum delay. Transportation Science, no. 1, 1967, pp. 81-94.

12. Day, C. M., R. Haseman, H. Premachandra, T. M. Brennan, J. S. Wasson, J. R. Sturdevant, 
and D. M. Bullock. Evaluation of Arterial Signal Coordination: Methodologies for Visualizing High-Resolution Event Data and Measuring Travel Time. Transportation Research Record: Journal of the Transportation Research Board, no. 2192, 2010, pp. 37-49.

13. Hu, H., and H. Liu. Arterial offset optimization using archived high-resolution. Transportation Research Part C, no. 37, October 2013, pp. 131-144.

14. Gartner, N., and R. Deshpande. Dynamic Programming Approach. Transportation Research Record: Journal of the Transportation Research Board, 2013, pp. 84-91.

15. Day, C. M., T. M. Brenna, A. M. Hainen, S. M. Remias, H. Premachandra, J. R. Sturdevant, G. Richards, J. S. Wasson, and D. M. Bullock. Reliability, Flexibility, and Environmental Impact of Alternative Objective Functions for Arterial Offset Optimization. Transportation Research Record: Journal of the Transportation Research Board, no. 2259, 2011, pp. 8-22.

16. Day, C. M., and D. M. Bullock. Computational Efficiency of Alternative Algorithms for Arterial Offset Optimization. Transportation Research Record: Journal of the Transportation Research Board, no. 2259, 2011, pp. 37-47.

17. Li, H., S. M. Lavrenz, C. M. Day, A. Stevens, J. R. Sturdevant, and D. M. Bullock. Quantifying the Benefits of Signal Timing Maintenance using Both Travel Time and Travel Time Reliability Measures. Transportation Research Record: Journal of the Transportation Research Board, 2016.

18. Wasson, J. S., J. R. Sturdevant, and D. M. Bullock. Real-time Travel Time Estimates Using Media Access Control Address Matching. ITE Journal, Vol. 78, no. 6, June 2008, pp. 20-23.

19. Day, C. M., T. Brennan, A. Hainen, S. Remias, and D. Bullock. Roadway System Assessment Using Bluetooth-Based Automatic Vehicle Identification Travel Time Data. Purdue University, West Lafayette, IN, Monograph 2012.

20. Quayle, S. M., P. Koonce, D. Depencier, and D. M. Bullock. Arterial Performance Measures with Media Access Control Readers: Portland, Oregon Pilot Study. Transportation Research Record: Journal of the Transportation Research Board, no. 2192, 2010, pp. 185-193.

21. Remias, S., A. Hainen, C. Day, T. Brennan, H. Li, E. Rivera-Hernandez, J. Sturdevant, S. Young, and D. Bullock. Performance Characterization of Arterial Traffic Flow with Probe Vehicle Data. Transportation Research Record: Journal of the Transportation Research Board, no. 2380, 2013, pp. 10-21.

22. Day, C. M., D. M. Bullock, H. Li, S. M. Remias, A. H. Hainen, R. S. Freije, A. L. Stevens, J. R. Sturdevant, and T. M. Brennan. Performance Measures for Traffic Signal Systems: An Outcome-Oriented Approach. Purdue University, West Lafayette, IN, Monograph 2014.

23. Jackson, W., and J. Jucker. An empirical study of travel time variability and travel choice behavior. Transportation Science, Vol. 16, 1982, pp. 460-475.

24. Cambridge Systematics, ICF International. Value of Travel Time Reliability: Synthesis Report \& Workshop Working Paper. in SHRP 2 Workshop on the Value of Travel Time Reliability, Washington, DC, 2012.

25. Schrank, D., B. Eisele, and T. Lomax. The Urban Mobility Report. 2012.

26. Small, K., R. Noland, X. Chiu, and D. Lewis. NCHRP Report 431 - Valuation of Travel Time Savings and Predictability in Congested Conditions for Highway User-Cost Estimation. Washington, DC, 1999.

27. Kittleson \& Associates, Inc. SHRP 2 Project L17 Guidebook: Placing a Value on Travel- 
Time Reliability. Washington, DC, 2013.

28. Litman, T. "Travel Time", Transportation Cost and Benefit Analysis. Victoria Transport Policy Institute, 2009. http://www.vtpi.org/tca/tca0502.pdf.

29. Noland, R., and K. Small. Travel-time uncertainty, departure time choice, and the cost of morning commutes. Transportation Research Record, Vol. 1493, 1995, pp. 150-158.

30. de Jong, G., S. Bakker, M. Pieters, and P. Wortelboer-van Donselaar. New Values of Time and Reliability in Freight Transport in the Netherlands. Rotterdam, 2004.

31. Fosgerau, M., K. Hjorth, C. Brems, and D. Fukuda. Travel time variability - Definition and valuation. Copenhagen, 2008. 


\section{Report Sponsor}

The "Small Business Innovation Development Act of 1982" (Pub. L. No. 97-219), along with reauthorizing legislation (Pub. L. No. 99-443 and Pub. L. No. 102-564, the "Small Business Research and Development Enhancement Act of 1992"), seeks to encourage the initiative of the private sector and to use small business effectively to meet federal research and development objectives. To comply with statutory obligations of the Act, the U.S. Department of Transportation established the Small Business Innovation Research (SBIR) Program, which conforms to the guidelines and regulations provided by the Small Business Administration. Annually, small businesses are solicited to submit innovative research proposals that address the high-priority requirements of the U.S. Department of Transportation and that have potential for commercialization.

This report was developed through a partnership between Traffax, Inc., and Purdue University with funding from a Phase III SBIR contract (DTFH6114C00035) with the Federal Highway Administration. The project, entitled "Sensor Fusion and MOE Development for Off-Line Traffic Analysis of Real Time Data," created and refined methods and tools for the characterization of performance along arterial corridors.

\section{Publication}

This report is part of a series of reports published in collaboration with USDOT, Traffax, Inc., and Purdue University. The full report series is available for download at http://docs.lib.purdue .edu/apmtp/.

\section{Open Access and Collaboration with Purdue University}

The Indiana legislature established the Joint Highway Research Project in 1937. In 1997, this collaborative venture between the Indiana Department of Transportation and Purdue University was renamed as the Joint Transportation Research Program (JTRP) to reflect state and national efforts to integrate the management and operation of various transportation modes. Since 1937, the JTRP program has published over 1,600 technical reports. In 2010, the JTRP partnered with the Purdue University Libraries to incorporate these technical reports in the University's open access digital repository and to develop production processes for rapidly disseminating new research reports via this repository. Affiliated publications have also recently been added to the collection. As of 2017, the JTRP collection had over 1.5 million downloads, with some particularly popular reports having over 20,000 downloads. 